\title{
Utilization and Outcomes of Postcardiotomy Mechanical Circulatory Support
}

\author{
Nicholas Hess ${ }^{1}$, Yisi Wang ${ }^{2}$, and Arman Kilic ${ }^{3}$ \\ ${ }^{1}$ University of Pittsburgh Medical Center \\ ${ }^{2}$ University of Pittsburgh Medical Center Health System \\ ${ }^{3}$ Medical University of South Carolina
}

August 1, 2021

\begin{abstract}
Background: This study evaluated the utilization and outcomes of postcardiotomy mechanical circulatory support (MCS). Methods: This was a retrospective, single institution analysis of adult cardiac surgery cases that required de novo MCS following surgery from 2011-2018. Patients that were bridged with MCS to surgery were excluded. The primary outcomes were early operative mortality and longitudinal survival. Secondary outcomes included postoperative complications, and five-year all-cause readmission. Results: 533 patients required de novo postcardiotomy MCS, with the most commonly performed procedure being isolated coronary artery bypass grafting (29.8\%). Median cardiopulmonary bypass and cross clamp times were 185 (IQR $123-$ 260) minutes and 122 (IQR 81-179) minutes, respectively. A total of 442 (82.9\%) of patients were supported with intra-aortic balloon pump counterpulsation, 23 (4.3\%) with an Impella device, and 115 (21.6\%) with extracorporeal membrane oxygenation. Three $(0.6 \%)$ patients had an unplanned ventricular assist device placed. Operative mortality was $29.8 \%$. Longitudinal survival was $56.1 \%$ and $43.0 \%$ at 1 - and 5-years, respectively. Survival was lowest in those supported with ECMO and highest with those supported with an Impella $(\mathrm{P}<0.001)$. Freedom from readmission was $61.4 \%$ at 5 -years. Postoperative ECMO was an independent predictor of mortality (HR 5.1, 95\% CI 2.0-12.9, P<0.001), but none of the MCS types predicted long-term hospital readmission after risk adjustment. Conclusions: Postcardiotomy MCS is associated with high operative mortality. Even patients that survive to discharge have compromised longitudinal survival, with nearly only half surviving to 1-year. Close follow-up and early referral to advanced heart failure specialists may be prudent in improving these outcomes.
\end{abstract}

\section{Introduction}

Postcardiotomy cardiogenic shock (PCCS), defined by inadequate end-organ perfusion due to low cardiac output, occurs after $1-5 \%$ of cardiac surgical procedures, and in about $1 \%$ of cases, patients may require postoperative mechanical circulatory support (MCS). ${ }^{1,2}$ The typical presentation of PCCS is decreasing cardiac function along with the difficulty or inability to wean from cardiopulmonary bypass without high-dose inotropic support and/or advanced MCS. Current MCS strategies include the use of intra-aortic balloon (IABP) counterpulsation, extracorporeal membrane oxygenation (ECMO), percutaneously-implanted or surgically implanted left ventricular assist devices, or a combination of devices. ${ }^{1}$ Despite advances in the development of support strategies, in-hospital mortality following PCCS remains high, with reports ranging from $40-90 \% \cdot{ }^{3-10}$

Due to the high costs of MCS usage following PCCS, along with the propensity for increased rates of further complication, prolonged intensive care and hospital stays, and ultimately high rate of death, it is often debated whether these measures are beneficial or futile. Furthermore, the long-term outcomes in survivors of PCCS have not been well-studied. Therefore, this study aimed to investigate our experience in using de novo MCS for PCCS following cardiac surgery, and examine short and long-term outcomes. 


\section{Materials and Methods}

\section{Study Population}

This was a retrospective analysis of a single institutional experience of adult patients (18 years or older) who underwent cardiac surgery at a multi-hospital health system between January 2011 and June 2018. Patients were included if they were placed on de novo MCS either intraoperatively or postoperatively. Patients who were supported with MCS prior to surgery were excluded. This study was approved by the Institutional Review Board at the University of Pittsburgh (MOD18120143-003, approved 3/9/2020). Patient consent was waived due to retrospective nature of the study.

\section{Primary and Secondary Outcomes}

The primary outcomes of this study were operative mortality and longitudinal survival. Operative mortality was defined as occurring within 30 days of the operation or in-hospital during the index hospitalization following the operation. Secondary outcomes included postoperative complications and five-year all-cause hospital readmission.

\section{Statistical Analysis}

Continuous data are presented as mean ( \pm standard deviation) for normally distributed variables or median [interquartile range (IQR)] for non-normally distributed variables. Categorical data are displayed as number (percentage). Kaplan Meier analysis was used to evaluate five-year survival and cumulative incidence of all-cause readmission.

Cox proportional hazards modeling was used to model postoperative mortality. In this model, all baseline characteristics and risk factors were assessed in a univariable model. Those with significant associations with mortality $(\mathrm{P}<0.05)$ were considered for inclusion in the final multivariable model. Backwards, stepwise elimination was performed to create the final model with covariable inclusion of $\mathrm{P}<0.2$ into the final model. Significant covariable interactions and multicollinearity were investigated.

Competing risk regression was used to model all-cause hospital readmission. In this model, death was the competing event. Baseline characteristics and risk factors were assessed in a univariable model, and those with significant associations $(\mathrm{P}<0.05)$ with all-cause readmissions were included in the final multivariable model. Statistical analyses were performed using SAS version 9.2 software (SAS Institute, Cary, NC).

\section{Results}

A total of 533 patients were included in this study. Baseline characteristics and preoperative comorbidities are presented inTable 1 . The majority of patients in this cohort were male (333 [63.4\%]) and of white race $(487[91.4 \%])$. A total of $310(58.2 \%)$ cases were performed as an urgent procedure, and $62(11.6 \%)$ were categorized as emergent or salvage procedures. Median Society of Thoracic Surgeons predicted risk of mortality was $3.8 \%$ (IQR $1.9 \%$ to $7.9 \%$ ).

The most common procedure performed was isolated coronary arterial bypass grafting (CABG), performed in $159(29.8 \%)$ cases. Other commonly performed procedures were double valve interventions (84 [15.8\%]) and combined CABG and aortic valve replacement $(60[11.3 \%])$. Operative characteristics are displayed in Table 2 . Cardiopulmonary bypass was utilized in $91.6 \%$ of cases with a median perfusion time and cross clamp time of 185 minutes (IQR 123 to 260) and 122 minutes (IQR 81 to 179), respectively.

Intraoperatively, or within the postoperative period, a total of $442(82.9 \%)$ of patients had an IABP placed (Table 3 ). A total of 23 (4.3\%) had an Impella device placed, and 115 (21.6\%) were placed on extracorporeal membrane oxygenation support. Three $(0.6 \%)$ patients had an unplanned ventricular assist device placed. Most (487 [91.37\%]) patients were supported with one circulatory support device, while 4 (0.75\%) patients were exposed to three different forms of MCS during the intraoperative and postoperative period.

Postoperative outcomes are presented in Table 4 . In this cohort, operative mortality was $29.8 \%$. Blood products were administered in $80.9 \%$ of patients, and the rate of reoperation was $46.5 \%$. Other complications 
included prolonged mechanical ventilation (334 [62.7\%]), renal failure (170 [31.9\%]), pneumonia (116 [21.8\%]), and stroke $(31$ [17.1\%]). Patients spent a median time of 124 hours in an intensive care unit setting.

\section{Long-Term Survival}

Median follow up was 2.28 years (IQR 0.04 to 4.50 years). One- and five-year unadjusted actuarial survival was $56.1 \%$ and $43.0 \%$ for the entire cohort, respectively (Figure 1A ). Figure 1Bdisplays unadjusted survival, stratified by mechanism of MCS. In this analysis, patients were categorized by the highest level of support used $(\mathrm{ECMO}>$ Impella $>$ IABP). At one and five years, actuarial survival was highest in patients bridged with an Impella device and lowest in patients bridged with ECMO.

Cox proportional hazards modeling was performed to identify predictors of mortality in patients bridged with MCS from CBP. In a univariable analysis, postoperative IABP insertion (HR 1.45, 95\% CI 1.00 to 2.10, $\mathrm{P}=0.05$ ), and either intraoperative (HR $1.59,95 \%$ CI 1.12 to $2.26, \mathrm{P}<0.001$ ) or postoperative (HR 2.52, 95\% CI 1.82 to $3.49, \mathrm{P}<0.001)$ ECMO insertion were associated with increased hazards for mortality. Usage of an Impella device, either intraoperatively (HR $0.54,95 \%$ CI 0.23 to $1.32, \mathrm{P}=0.18$ ) or postoperatively (HR 0.90 , $95 \%$ CI 0.37 to $2.17, \mathrm{P}=0.81$ ) was not found to be associated with mortality. There were too few patients with durable ventricular assist device insertion to model.

When adjusted for other significant baseline risk factors, postoperative ECMO cannulation was associated with a five-fold increased hazards for mortality in the final multivariable model (HR 5.12, 95\% CI 2.04 to 12.85, $\mathrm{P}<0.001$ ) (Table 5 ). Intraoperative ECMO cannulation did not reach statistical significance for mortality hazard (HR 2.47, 95\% CI 0.96 to $6.33, \mathrm{P}=0.06$ ). Other factors associated with increased hazards for mortality include increasing age (per year, HR 1.04, 95\% CI 1.01 to $1.07, \mathrm{P}=0.01$ ), presence of peripheral vascular disease (HR 3.55, 95\% CI 1.93 to $6.52, \mathrm{P}<0.001$ ), and emergent operative status (HR 5.90, 95\% CI 1.89 to $18.44, \mathrm{P}<0.001)$. After risk adjustment, bridging with either Impella or IABP were not found to be associated with mortality, and were removed from the final model.

\section{Long-Term Readmission}

Thirty-day readmission was $13.1 \%$. At one and five years, $28.3 \%$ and $38.7 \%$ of patients were readmitted to the hospital for any reason (Figure 2 ). Overall rate of rate of cardiac-related readmission in this study period was $34.2 \%$.

Competing risk regression was used to model risk factors for all-cause readmission. In a univariable analysis, postoperative ECMO (HR 0.37, 95\% CI 0.19 to $0.74, \mathrm{P}=0.01$ ) was associated with a decreased hazards for readmission, which may reflect the high in-hospital mortality associated with its usage. Implantation of a ventricular assist device was associated with a four-fold risk of readmission (HR 4.31, 95\% CI 2.80 to 6.63, $\mathrm{P}<0.001)$.

In a multivariable model, none of the bridging strategies were significantly associated with readmission after risk adjustment (Table 6 ). In this model, increasing baseline creatinine level (per $1 \mathrm{mg} / \mathrm{dL}, \mathrm{HR} 1.86,95 \%$ CI 1.03 to $3.36, \mathrm{P}=0.04$ ) was associated with increased risk of readmission. However, preoperative dialysis dependency was associated with drastically reduced hazards for readmission (HR 0.07, 95\% CI 0.01 to 0.75 , $\mathrm{P}=0.03$ ), likely representing a high operative mortality in this subpopulation.

\section{Discussion}

The development of postcardiotomy cardiogenic shock is a feared complication following cardiac surgery. Though risk factors for this condition are not well described, many cases are often attributed to poor preoperative cardiac function, prolonged cardiopulmonary bypass and cross-clamp times, poor myocardial protection, and or ongoing ischemia. Once believed to be a mortal complication, early mortality following these cases have been high, ranging from $40 \%$ to $90 \%,{ }^{11,12}$ with rates highest following coronary bypass grafting or combined bypass grafting and valvular operations. ${ }^{13}$ Due to this low rate of survival, the discussion regarding the practicality of postoperative transition to MCS, especially higher-level forms such as ECMO, remains ongoing in efforts to mitigate futile and costly practices. 
The interpretation of the results from our series can be viewed from different perspectives. The fact that $56 \%$ survived to 1-year suggests that postcardiotomy MCS in general is not a futile practice, and that patients can survive not only the early postoperative period but longitudinally for several years as well. Even in those requiring ECMO support, over one third of these patients survived to one year, with a quarter reaching fiveyear survival. These outcomes are comparable to those reported by Biancari and colleagues, ${ }^{14}$ who reported a five-year survival of $27.7 \%$ in a series of 665 patients bridged with veno-arterial ECMO following development of postcardiotomy shock. In their series, increased age was the greatest pre-ECMO predictor of mortality for these patients, with a five-year survival of $13.0 \%$ in those 80 years or older. In our analysis, we observed a $4 \%$ increase in hazards for mortality per year of age (HR 1.04, 95\% CI 1.01 to $1.07, \mathrm{P}=0.01$ ), once again drawing attention to this pre-MCS risk factor. Thus age and overall life expectancy should be considered prior to initiation of MCS for this advanced age subset.

Another interpretation of our data is that nearly half of patients die within 1-year of postcardiotomy MCS support. Although not all of these patients likely succumb to advanced heart failure, close follow-up of this patient cohort appears to be prudent. Other measures and interventions such as continued rehabilitation, prevention of infection, nutritional optimization, and early referral to advanced heart failure providers may all be important in improving survival and quality of life in this challenging cohort.

The choice of MCS for the patient in postcardiotomy shock is nuanced, and decisions are often tailored to the specific needs of the patient. For the patient with depressed left ventricular function and/or high inotropic requirement in order to separate from cardiopulmonary bypass, an IABP is often inserted as a first measure to support hemodynamic performance and/or coronary perfusion. Should these measures be insufficient, or the patient develops overwhelming right ventricular dysfunction/failure and/or pulmonary insufficiency, consideration for ECMO cannulation is entertained.

Insertion of a durable left ventricular assist device or a temporary device such as the Impella is not routinely considered at the time of index operation. In these patients, the more typical course is the presence of preexisting ventricular dysfunction that fails to improve after surgical intervention and/or revascularization, or more rarely, left ventricular dysfunction that develops as a consequence of the operation without recovery. For these patients, they may be initially stabilized with another form of MCS, and once left ventricular recovery is deemed improbable, these devices are considered. Depending on baseline characteristics at this time, durable ventricular assist therapy may be chosen, or an Impella may be inserted with the goal of transplantation. The benefits of durable or temporary ventricular assist devices is their ability to unload the left ventricle, reduce ventricular distension, and thereby improve myocardial recovery. Several types of MCS devices may also be used in combination to achieve the goals of left ventricular unloading, oxygenation, and improved perfusion.

One of the most important tenets of MCS is early initiation. This concept was solidified in our analysis where postoperative placement of ECMO had a greater impact on mortality risk than intraoperative placement. Patients who are weaned from cardiopulmonary bypass on very high levels of inotropic support and with marginal hemodynamics typically will deteriorate over the ensuing minutes or hours. Poor perfusion and associated acidosis can lead to lethal arrhythmias or end organ failure in a short period of time and dramatically increase mortality risk in these patients. As has been shown in the cardiogenic shock literature, early MCS including in the postcardiotomy setting should be employed to help offload demands of the myocardium and to improve perfusion and limit acid-base disturbances.

\section{Limitations}

This study was prone to limitations. This study was a retrospective review of patients who received unplanned de novo MCS after cardiac surgery, and thus was not randomized. As such, direct comparisons of MCS strategies are not possible within the limits of this study. Mechanical support may be initiated for various reasons, and the choice of bridging support is often tailored to the individual needs of the patient or preferences of the surgeon. As a result, selection bias likely exists. The scope of this study is to report upon a large experience of MCS support following cardiac surgery and to evaluate both early and longitudinal 
outcomes, and to not advocate the usage of one form of support over another.

\section{Conclusions}

In this review of 533 patients requiring unplanned MCS following conventional cardiac surgical procedures, we observed a high rate of operative mortality and morbidity, with the highest rate of mortality in those supported with ECMO. Even though the majority survive the perioperative period, nearly half of the patients had died by one year. These findings suggest that continued surveillance and close follow-up of these patients is important to improving longitudinal outcomes in this challenging patient subset.

\section{Acknowledgements}

none

\section{Disclosures}

Arman Kilic, MD is on the medical advisory board for Medtronic, Inc. This affiliation does not create any direct conflicts with the contents of this manuscript.

\section{References}

1. Chen K, Hou J, Tang H, Hu S. Concurrent Implantation of Intra-Aortic Balloon Pump and Extracorporeal Membrane Oxygenation Improved Survival of Patients With Postcardiotomy Cardiogenic Shock. Artif Organs . 2019;43(2):142-149. doi:10.1111/aor.13317

2. Golding LAR. Postcardiotomy mechanical support. Semin Thorac Cardiovasc Surg . 1991;3(1):29-32. doi:10.5555/uri:pii:1043067991900518

3. Khorsandi M, Dougherty S, Bouamra O, Pai V, Curry P, Tsui S, Clark S, Westaby S, Al-Attar N, Zamvar V. Extra-corporeal membrane oxygenation for refractory cardiogenic shock after adult cardiac surgery: A systematic review and meta-analysis. J Cardiothorac Surg . 2017;12(1). doi:10.1186/s13019-017-0618-0

4. Griffith BP, Anderson MB, Samuels LE, Pae WE, Naka Y, Frazier OH. The RECOVER I: A multicenter prospective study of Impella 5.0/LD for postcardiotomy circulatory support. J Thorac Cardiovasc Surg . 2013;145:548-554. doi:10.1016/j.jtcvs.2012.01.067

5. Fux T, Holm M, Corbascio M, Lund LH, van der Linden J. Venoarterial extracorporeal membrane oxygenation for postcardiotomy shock: Risk factors for mortality. J Thorac Cardiovasc Surg . 2018;156(5):18941902.e3. doi:10.1016/j.jtcvs.2018.05.061

6. Chen F, Wang L, Shao J, Wang H, Hou X, Jia M. Survival following venoarterial extracorporeal membrane oxygenation in postcardiotomy cardiogenic shock adults. Perfus (United Kingdom) . 2020;35(8):747-755. doi:10.1177/0267659120931306

7. David CH, Quessard A, Mastroianni C, Hekimian G, Amour J, Leprince P, Lebreton G. Mechanical circulatory support with the Impella 5.0 and the Impella Left Direct pumps for postcardiotomy cardiogenic shock at la Pitié-Salpêtrière Hospital. Eur J Cardio-thoracic Surg . 2020;57(1):183-188. doi:10.1093/ejcts/ezz179

8. Khorsandi M, Shaikhrezai K, Prasad S, Pessotto R, Walker W, Berg G, Zamvar V. Advanced mechanical circulatory support for post-cardiotomy cardiogenic shock: A 20-year outcome analysis in a non-transplant unit.J Cardiothorac Surg . 2016;11(1):29. doi:10.1186/s13019-016-0430-2

9. Muehrcke DD, McCarthy PM, Stewart RW, Foster RC, Ogella DA, Borsh JA, Cosgrove DM. Extracorporeal membrane oxygenation for postcardiotomy cardiogenic shock. Ann Thorac Surg . 1996;61(2):684-691. doi:10.1016/0003-4975(95)01042-4

10. Rastan AJ, Dege A, Mohr M, Doll N, Falk V, Walther T, Mohr FW. Early and late outcomes of 517 consecutive adult patients treated with extracorporeal membrane oxygenation for refractory postcardiotomy cardiogenic shock. J Thorac Cardiovasc Surg . 2010;139(2). doi:10.1016/j.jtcvs.2009.10.043 
11. Provaznik Z, Philipp A, Zeman F, Camboni D, Schmid C, Floerchinger B. Extracorporeal Life Support in Postcardiotomy Cardiogenic Shock: A View on Scenario, Outcome, and Risk Factors in 261 Patients. Thorac Cardiovasc Surg. Published online 2020. doi:10.1055/s-0040-1714746

12. Loungani RS, Fudim M, Ranney D, Kochar A, Samsky MD, Bonadonna D, Itoh A, Takayama H, Takeda K, Wojdyla D, DeVore AD, Daneshmand M. Contemporary Use of Venoarterial Extracorporeal Membrane Oxygenation: Insights from the Multicenter RESCUE Registry. J Card Fail . 2021;27(3). doi:10.1016/j.cardfail.2020.11.026

13. Kowalewski M, Zieliński K, Brodie D, MacLaren G, Whitman G, Raffa GM, Boeken U, Shekar K, Chen Y-S, Bermudez C, D'Alessandro D, Hou X, Haft J, Belohlavek J, Dziembowska I, Suwalski P, Alexander P, Barbaro RP, Gaudino M, et al. Venoarterial Extracorporeal Membrane Oxygenation for Postcardiotomy Shock-Analysis of the Extracorporeal Life Support Organization Registry. Crit Care Med . 2021;Publish Ah. doi:10.1097/CCM.0000000000004922

14. Biancari F, Perrotti A, Ruggieri VG, Mariscalco G, Dalén M, Dell'Aquila AM, Jónsson K, Ragnarsson S, Di Perna D, Bounader K, Gatti G, Juvonen T, Alkhamees K, Yusuff H, Loforte A, Lechiancole A, Chocron S, Pol M, Spadaccio C, et al. Five-year survival after post-cardiotomy veno-arterial extracorporeal membrane oxygenation. Eur Hear Journal Acute Cardiovasc Care . Published online January 12, 2021. doi:10.1093/ehjacc/zuaa039

15. Durmaz I, Buket S, Atay Y, Yagdi T, Ozbaran M, Boga M, Alat I, Guzelant A, Basarir S. Cardiac surgery with cardiopulmonary bypass in patients with chronic renal failure. J Thorac Cardiovasc Surg . 1999;118(2):306-315. doi:10.1016/S0022-5223(99)70221-7

16. De Peppo AP, Nardi P, De Paulis R, Pellegrino A, Forlani S, Scafuri A, Chiariello L. Cardiac surgery in moderate to end-stage renal failure: Analysis of risk factors. Ann Thorac Surg . 2002;74(2):378-383. doi:10.1016/S0003-4975(02)03711-6

17. Li X, Zhang S, Xiao F. Influence of chronic kidney disease on early clinical outcomes after off-pump coronary artery bypass grafting.J Cardiothorac Surg . 2020;15(1):199. doi:10.1186/s13019-020-01245-5

18. Leontyev S, Davierwala PM, Gaube L-M, R $\backslash$ euro Ohrig KA, Lehmann S, Holzhey DM, Noack T, Misfeld M, Mohr FW. Outcomes of Dialysis-Dependent Patients After Cardiac Operations in a Single-Center Experience of 483 Patients. Published online 2017. doi:10.1016/j.athoracsur.2016

19. Zimmet AD, Almeida A, Goldstein J, Shardey GC, Pick AW, Lowe CE, Jolley DJ, Smith JA. The outcome of cardiac surgery in dialysis-dependent patients. Hear Lung Circ . 2005;14(3):187-190. doi:10.1016/j.hlc.2005.02.006

20. Kirklin JK, Naftel DC, Kormos RL, Pagani FD, Myers SL, Stevenson LW, Givertz MM, Young JB. Quantifying the effect of cardiorenal syndrome on mortality after left ventricular assist device implant. $J$ Hear Lung Transplant . 2013;32(12):1205-1213. doi:10.1016/j.healun.2013.09.001

21. Kashani K, Ostermann M. Optimizing renal replacement therapy for patients who need extracorporeal membrane oxygenation: Cross-talk between two organ support machines. BMC Nephrol . 2019;20(1):404. doi:10.1186/s12882-019-1602-9

Table 1. Patient demographics and preoperative comorbidities of patients who were supported with de novo mechanical circulatory support following cardiac surgery

\begin{tabular}{ll}
\hline Characteristics & $\mathrm{N}(\%)$ or Median (IQR) N=533 \\
\hline Female & $195(36.59 \%)$ \\
Race & \\
White & $487(91.37 \%)$ \\
Black & $35(6.57 \%)$
\end{tabular}




\begin{tabular}{ll}
\hline Characteristics & $\mathrm{N}(\%)$ or Median $(\mathrm{IQR}) \mathrm{N}=533$ \\
\hline Other & $11(2.06 \%)$ \\
Age $($ years $)$ & $67.00(58.00-75.00)$ \\
$\mathrm{BMI}\left(\mathrm{kg} / \mathrm{m}^{2}\right)$ & $28.13(24.49-32.50)$ \\
BSA $\left(\mathrm{m}^{2}\right)$ & $1.98 \pm 0.27$ \\
Diabetes mellitus & $222(41.65 \%)$ \\
Dialysis dependency & $23(4.32 \%)$ \\
Chronic obstructive pulmonary disease & $173(32.46 \%)$ \\
Hypertension & $433(81.24 \%)$ \\
Immunosuppression & $43(8.07 \%)$ \\
Cerebrovascular disease & $133(24.95 \%)$ \\
Peripheral vascular disease & $123(23.08 \%)$ \\
Previous myocardial infarction & $300(56.29 \%)$ \\
Cardiac symptoms at admission & \\
No symptoms & $111(20.83 \%)$ \\
Symptoms unlikely to be ischemia & $46(8.63 \%)$ \\
Stable angina & $22(4.13 \%)$ \\
Unstable angina & $83(15.57 \%)$ \\
NSTEMI & $101(18.95 \%)$ \\
STEMI & $27(5.07 \%)$ \\
Symptoms equivalent to angina & $1(0.19 \%)$ \\
Other & $142(26.64 \%)$ \\
Operative status & \\
Elective & $161(30.21 \%)$ \\
Urgent & $310(58.16 \%)$ \\
Emergent or salvage & $62(11.63 \%)$ \\
NYHA class symptoms & \\
I & $244(45.78 \%)$ \\
II & $22(4.13 \%)$ \\
III & $100(18.76 \%)$ \\
IV & $167(31.33 \%)$ \\
Previous congestive heart failure & $246(46.15 \%)$ \\
History of cardiac arrhythmia & $208(39.02 \%)$ \\
Preoperative creatinine $(\mathrm{mg} / \mathrm{dL})$ & $1.10(0.90-1.40)$ \\
Preoperative total bilirubin $(\mathrm{mg} / \mathrm{dL})$ & $0.70(0.50-1.00)$ \\
Preoperative albumin $(\mathrm{g} / \mathrm{dL})$ & $3.60(3.20-3.80)$ \\
Preoperative LVEF & $45.00(28.00-58.00)$ \\
\hline &
\end{tabular}

$\mathrm{BMI}=$ body mass index; $\mathrm{BSA}=$ body surface area; $\mathrm{IQR}=$ interquartile range; $\mathrm{LVEF}=$ left ventricular ejection fraction; NSTEMI = non-ST-elevation myocardial infarction; NYHA = New York Heart Association; STEMI $=$ ST-elevation myocardial infarction

Table 2. Operative details and postoperative support for patients who were started on mechanical circulatory support following cardiac surgery

\begin{tabular}{ll}
\hline Characteristic & $\mathrm{N}(\%)$ or Median (IQR) \\
\hline STS predicted risk of mortality (\%) & $3.83(1.86-7.90)$ \\
Cardiopulmonary bypass utilization & $488(91.56 \%)$ \\
Perfusion time (minutes) & $185.0(123.5-260.0)$ \\
Cross clamp time (minutes) & $122.0(81.00-179.0)$
\end{tabular}




\begin{tabular}{ll}
\hline Characteristic & $\mathrm{N}(\%)$ or Median (IQR) \\
\hline Operation performed & $41(7.69 \%)$ \\
Aortic Root & $60(11.26 \%)$ \\
CABG + AVR & $48(9.01 \%)$ \\
CABG + MVr/MVR & $84(15.76 \%)$ \\
Double Valve & $34(6.38 \%)$ \\
Isolated AVR & $159(29.83 \%)$ \\
Isolated CABG & $31(5.82 \%)$ \\
Isolated MVr/MVR & $4(0.75 \%)$ \\
Isolated TVR & $13(2.44 \%)$ \\
Triple Valve & $7(1.31 \%)$ \\
TAVR & $52(9.76 \%)$ \\
Other &
\end{tabular}

AVR, aortic valve replacement

CABG, coronary artery bypass grafting

IABP, intra-aortic balloon pump

$\mathrm{MVr}$, mitral valve repair

MVR, mitral valve replacement

STS, Society of Thoracic Surgeons

TAVR, transcatheter aortic valve replacement

TVR, tricuspid valve replacement

Table 3. Timing and indication of mechanical circulatory support usage

\begin{tabular}{ll}
\hline Variable & $\mathrm{N}(\%)$ \\
\hline $\begin{array}{l}\text { Intra-aortic balloon pump placement } \\
\text { Intraoperative }\end{array}$ & $352(66.04 \%)$ \\
Postoperative & $90(16.89 \%)$ \\
Intra-aortic balloon pump indications & \\
Hemodynamic instability & $201(45.48 \%)$ \\
PCI or other procedural & $12(2.71 \%)$ \\
Unstable angina & $2(0.45 \%)$ \\
Weaning from cardiopulmonary bypass & $210(47.51 \%)$ \\
Prophylatic & $17(3.85 \%)$ \\
Impella placement & $13(2.44 \%)$ \\
Intraoperative & $10(1.88 \%)$ \\
Postoperative & $15(65.22 \%)$ \\
Impella indications & $6(26.09 \%)$ \\
Hemodynamic instability & $2(8.70 \%)$ \\
Weaning from cardiopulmonary bypass \\
PCI or other procedural support \\
ECMO placement & $60(11.26 \%)$ \\
Intraoperative & $55(10.32 \%)$ \\
Postoperative &
\end{tabular}




\begin{tabular}{ll}
\hline Variable & $\mathrm{N}(\%)$ \\
\hline Cardiac failure & $72(62.61 \%)$ \\
Respiratory & $35(30.43 \%)$ \\
Rescue/salvage & $8(6.96 \%)$ \\
Ventricular assist device placement & $3(0.56 \%)$ \\
VAD indication & $1(33.33 \%)$ \\
Bridge to transplantation & $2(66.67 \%)$ \\
Destination therapy & $487(91.37 \%)$ \\
Total number of devices inserted & $42(7.88 \%)$ \\
1 & $4(0.75 \%)$ \\
3 &
\end{tabular}

$\mathrm{ECMO}=$ extracorporeal membrane oxygenation; $\mathrm{PCI}=$ percutaneous coronary intervention; VAD $=$ ventricular assist device

Table 4. Postoperative complications and outcomes following surgery

\begin{tabular}{ll}
\hline Adverse Event or Outcome & $\mathrm{N}(\%)$ or Median (IQR) \\
\hline Operative mortality & $159(29.83 \%)$ \\
Reoperation & $248(46.53 \%)$ \\
Blood product transfusion & $431(80.86 \%)$ \\
Prolonged mechanical ventilation & $334(62.66 \%)$ \\
Pneumonia & $116(21.76 \%)$ \\
Renal failure & $170(31.89 \%)$ \\
Stroke & $31(5.82 \%)$ \\
Sepsis & $43(8.07 \%)$ \\
Superficial wound infection & $12(2.25 \%)$ \\
Deep sternal wound infection & $2(0.38 \%)$ \\
Atrial fibrillation & $187(35.08 \%)$ \\
Total ICU hours & $123.5(70.83-292.00)$ \\
\hline
\end{tabular}

$\mathrm{ICU}=$ intensive care unit; IQR = interquartile range

Table 5. Multivariable Cox proportional hazards model for postoperative mortality

\begin{tabular}{llll}
\hline Covariable & Hazard Ratio & $95 \%$ Confidence Interval Limits & $95 \%$ Confidence Interval Lim \\
\hline ECMO & & & \\
None & Ref & Ref & Ref \\
Intraoperative cannulation & 2.47 & 0.96 & 6.33 \\
Postoperative cannulation & 5.12 & 2.04 & 12.85 \\
Race & & & Ref \\
White & Ref & Ref & 5.79 \\
Black & 1.40 & 0.34 & 37.04 \\
Other & 5.65 & 0.86 & 2.89 \\
Chronic obstructive pulmonary disease & 1.60 & 0.89 & 1.33 \\
Family history of CAD & 0.55 & 0.23 & 6.52 \\
Peripheral vascular disease & 3.55 & 1.93 & \\
Cardiac symptoms at admission & & &
\end{tabular}




\begin{tabular}{llll}
\hline Covariable & Hazard Ratio & $95 \%$ Confidence Interval Limits & $95 \%$ Confidence Interval Lim \\
\hline No symptoms & Ref & Ref & Ref \\
Symptoms unlikely to be ischemia & 1.54 & 0.54 & 4.42 \\
Stable angina & 0.18 & 0.02 & 1.81 \\
Unstable angina & 2.33 & 0.64 & 8.48 \\
NSTEMI & 1.73 & 0.49 & 6.11 \\
STEMI & 0.09 & 0.01 & 0.57 \\
Other & 0.75 & 0.30 & 1.86 \\
NYHA class symptoms & & & \\
I & Ref & Ref & Ref \\
II & 10.02 & 1.85 & 54.43 \\
III & 1.58 & 0.74 & 3.35 \\
IV & 1.86 & 0.83 & 4.20 \\
Operative status & & & \\
Elective & Ref & Ref & Ref \\
Urgent & 0.91 & 0.41 & 2.02 \\
Emergent/salvage & 5.90 & 1.89 & 18.44 \\
Procedure performed & & & \\
Isolated CABG & Ref & Ref & Ref \\
Aortic root & 0.53 & 0.13 & 2.25 \\
CABG + AVR & 2.62 & 0.97 & 7.06 \\
CABG + MVr/MVR & 0.18 & 0.05 & 0.62 \\
Double Valve & 0.70 & 0.18 & 2.64 \\
Single valve & 0.54 & 0.17 & 1.75 \\
Age, increasing, per year & 1.04 & 1.01 & 0.07 \\
Albumin (increasing, per $1 \mathrm{~g} / \mathrm{dL})$ & 0.31 & 0.16 & 1.04 \\
Preoperative LVEF (increasing, per 1\%) & 1.02 & 0.99 & 3.59 \\
Total bilirubin (increasing, per $1 \mathrm{mg} / \mathrm{dL})$ & 1.99 & 1.11 & \\
\hline & & &
\end{tabular}

$\mathrm{AVR}=$ aortic valve replacement; $\mathrm{BMI}=$ body mass index; $\mathrm{BSA}=$ body surface area; $\mathrm{CABG}=$ coronary artery bypass grafting; $\mathrm{CAD}=$ coronary artery disease; $\mathrm{ECMO}=$ extracorporeal membrane oxygenation; $\mathrm{LVEF}=$ left ventricular ejection fraction; $\mathrm{MVr}=$ mitral valve repair; $\mathrm{MVR}=$ mitral valve replacement; NSTEMI $=$ non-ST-elevation myocardial infarction; NYHA $=$ New York Heart Association; STEMI $=$ STelevation myocardial infarction

Table 6. Competing risk regression for all-cause hospital readmission

\begin{tabular}{llll}
\hline Covariable & Hazard Ratio & $95 \%$ Confidence Interval Limits & $95 \%$ Confidence Interval Li \\
\hline ECMO & & & Ref \\
Not used & Ref & Ref & 2.51 \\
Intraoperative cannulation & 0.90 & 0.33 & 2.00 \\
Postoperative cannulation & 0.46 & 0.11 & 1.01 \\
Preoperative LVEF (increasing, per 1\%) & 0.99 & 0.97 & 3.36 \\
Serum creatinine (increasing, per 1 mg/dL) & 1.86 & 1.03 & 2.22 \\
History of congestive heart failure & 1.18 & 0.62 & Ref \\
Cardiac symptoms at admission & & & 3.65 \\
No symptoms & Ref & Ref & 7.39 \\
Symptoms unlikely to be ischemia & 1.08 & 0.32 & 2.01
\end{tabular}




\begin{tabular}{llll}
\hline Covariable & Hazard Ratio & $95 \%$ Confidence Interval Limits & $95 \%$ Confidence Interval Li \\
\hline NSTEMI & 1.55 & 0.61 & 3.95 \\
STEMI & 1.30 & 0.25 & 6.71 \\
Other & 0.73 & 0.27 & 2.01 \\
Dialysis dependency & 0.07 & 0.01 & 0.75 \\
\hline
\end{tabular}

ECMO = extracorporeal membrane oxygenation; LVEF $=$ left ventricular ejection fraction; NSTEMI = non-ST-elevation myocardial infarction; STEMI = ST-elevation myocardial infarction

\section{Figure Legend}

Figure 1. Five-year actuarial survival in patients placed on de novo mechanical circulatory support following conventional cardiac surgical procedures. A) displays survival for the entire cohort, while B) stratifies patients by highest level of support utilized

Figure 2. Five-year all-cause readmission following de novo institution of mechanical circulatory support following conventional cardiac surgical procedures
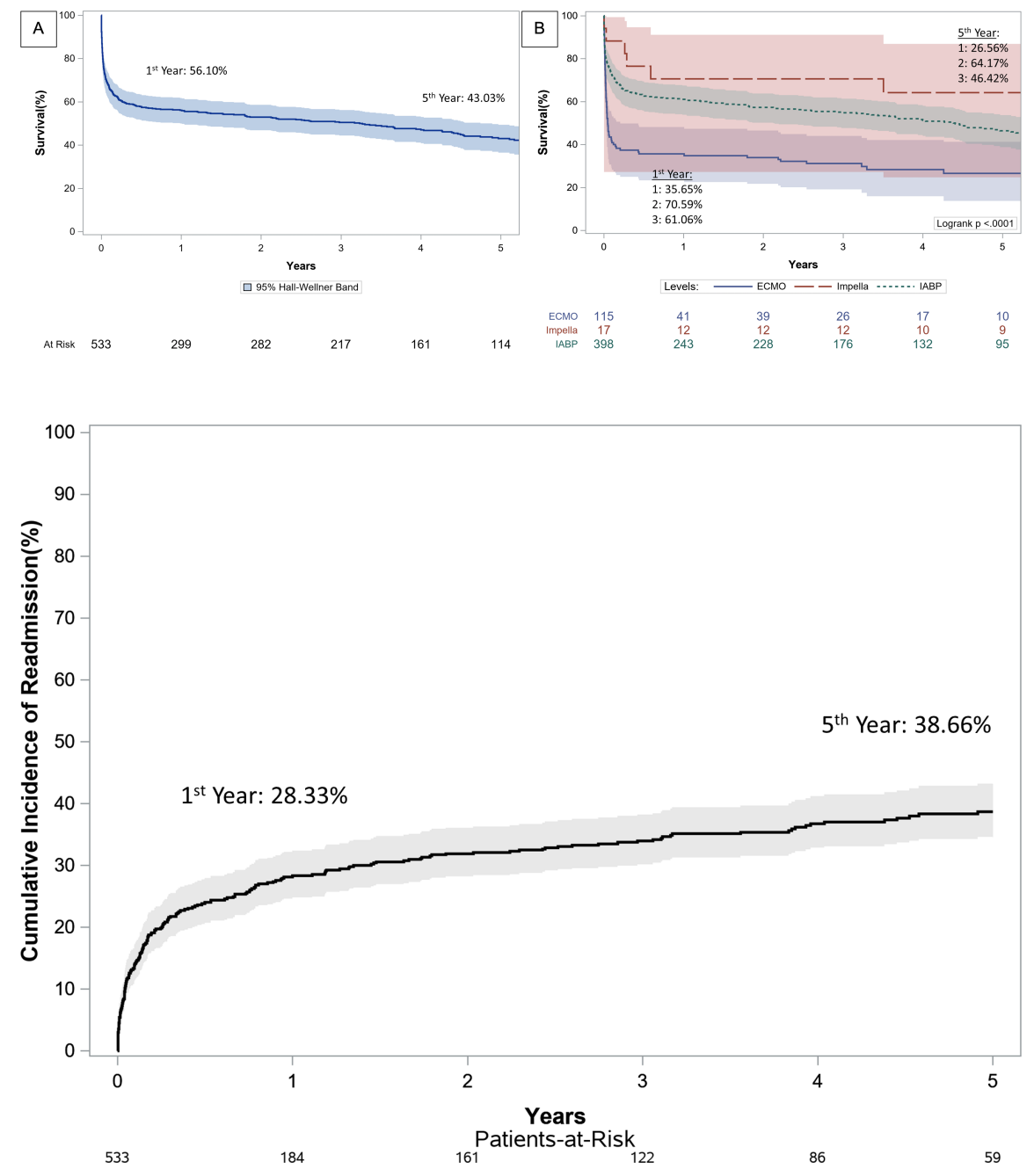